\title{
A Aquisição Espontânea de Habilidades Motoras no Contexto da Escola ${ }^{1}$
}

\author{
CLAUDIO TARSO DE J.S. NASCIMENTO \\ Departamento de Educação Física/FFCL-São José do Rio Pardo \\ claudiotarso@ig.com.br \\ ANA MARIA PELLEGRINI \\ Departamento de Educação Física/Unesp/Rio Claro \\ anapell@rc.unesp.br
}

\begin{abstract}
Resumo
O objetivo deste estudo foi identificar como crianças de 4/5 e 6/7 anos de idade se autoorganizam e aprendem habilidades motoras básicas quando brincam livremente na escola. Participaram deste estudo 24 crianças com idades entre $4 / 5$ e 6/7 anos que foram orientadas a brincar livremente. Algumas formas emergiam natural e espontaneamente entre as crianças como as corridas em linha reta e as corridas em círculo. Foram observadas três situações de aprendizagem: a) ações individuais, quando brincava sozinha explorando o espaço e o próprio corpo; b) imitação ou modelo, quando observava o que a outra estava fazendo; c) a busca de um parceiro, quando encontrava uma outra criança e juntas executavam uma ação motora. Os dados sugerem que formas de auto-organização emergem espontaneamente entre as crianças enquanto brincam. Concluímos que o processo de aprendizagem ocorre a partir das relações estabelecidas entre as crianças quando exploram suas próprias ações e passam a orientar as ações motoras de outras crianças.

Palavras-chave: desenvolvimento motor, auto-organização, habilidades motoras e aprendizagem.
\end{abstract}

\section{Resumen}

El objetivo de este estudio fue identificar como niños de 4-5 y 6-7 años de edad se autoorganizan y aprenden habilidades motoras básicas cuando juegan libremente en la escuela. Participaron de este estudio 24 niños de edades entre 4-5 y 6-7 años que fueron orientados para jugar libremente. Algunas formas surgían natural y espontaneamente entre los niños, como las carreras en línea recta y las carreras en círculo. Se observaron tres situaciones de aprendizado: a) acciones individuales, cuando jugaba solo explorando el espacio y el proprio cuerpo, b) imitación o modelo, cuando observaba lo que el otro estaba haciendo; c) la busca de un compañero, cuando encontraba otro niño y juntos realizaban una acción motora. Los datos sugieren que formas de auto-organización surgen espontaneamente entre los niños mientra juegan. Concluímos que el proceso de aprendizado ocurre a partir de las

1 Trabalho baseado em Dissertação de Mestrado do primeiro autor defendida no Instituto de Biociências da Unesp, Rio Claro. 
relaciones establecidas entre los niños cuando exploran sus proprias acciones y pasan a orientar las acciones motoras de otros niños.

Palabras-clave: desenvolvimiento motor, auto-organización, habilidades motoras y aprendizado.

\begin{abstract}
The aim of this study was to identify how 4-5/6-7 year old children learn basic motor skills while freely playing at school. Twenty-four children - aged between 4/5 and 6/7 - took part in this study. Children were instructed to play freely. Based on video analyses we observed that some forms emerged spontaneously among children and they were especially persistent in straight and crossed line running activities as well as circle formation. These activities originated in a natural and spontaneous way. We also observed the process of learning motor skills in three situations: a) Individual actions - when children played alone, exploring the context and their own body; b) Imitating or modeling - when children observed what other children were doing; c) Seeking a partner - when a child met another child and together they performed a motor action. These data suggest that self-organized forms emerge spontaneously among children while they play. We can also conclude that the learning process occurs when relationships are established among children while they explore their own actions and come to direct other children's motor actions.
\end{abstract}

Key words: motor development, self-organization, motor skills and learning. 


\section{INTRODUÇÃO}

De modo geral, o brincar é visto como um ato voluntário e espontâneo. A brincadeira possibilita à criança expressar-se e comunicar-se com as pessoas do contexto no qual está inserida. Podemos dizer ainda que o brincar é uma atividade natural e exploratória que assume papel fundamental no desenvolvimento do ser humano. A brincadeira apresenta um caráter global que permite à criança o desenvolvimento de suas habilidades nas dimensões física, motora, cognitiva, afetiva e social. O brincar proporciona à criança administrar suas próprias ações, sem ter a obrigação e pressão de se submeter a regras que são impostas por seus professores, ou outros adultos. O ato de brincar vem sendo apontado por pedagogos e psicólogos como fator primordial para o desenvolvimento e construção do conhecimento infantil (Kishimoto, 1996).

As crianças, enquanto brincam, são capazes de demonstrar situações de cooperação, entre elas, por intermédio da organização e reorganização de suas ações, cabendo-lhe a elaboração das regras que contribuirão para o desenvolvimento da brincadeira. Desta forma é garantido às crianças o direito de se expressarem com liberdade, colocando em prática todo o seu potencial, rico em imaginação e criatividade.

A brincadeira pode desenvolver-se em qualquer lugar: no clube, no bairro, em casa ou na escola. Dentro deste leque de opções, apontamos a escola como um espaço bastante favorável para que a criança explore seu potencial. É lamentável destacar que algumas escolas ainda concebam a idéia de que o tempo livre na escola, dedicado à realização de atividades lúdicas e recreativas, é um momento improdutivo, não contribuindo para a formação da criança. Assim, no contexto da escola, nem todos reconhecem no brincar, a riqueza de possibilidades que esta atividade proporciona. Mrech (1998) ressalta que a liberdade de expressão, apresentada pela criança, é freqüentemente reprimida pelos adultos, tanto na escola como em casa, onde são estabelecidas regras que deverão ser cumpridas. Quando não cumpridas, as crianças estarão sujeitas a punições. Podemos perceber claramente estas imposições e punições, quando a criança apresenta um comportamento diferente daquele que é imposto pela escola e, como conseqüência, perde o direito de participar do recreio e das aulas de Educação Física. Outra regra preestabelecida na escola é a separação entre meninos e meninas, tanto na disposição das carteiras ou mesinhas em sala de aula quanto na formação de filas que são utilizadas com grande freqüência para a locomoção das crianças na escola.

Existem dados na literatura que apontam ser o recreio o local ou o momento em que a agressividade das crianças e adolescentes se manifesta 
(Marques, Neto, Pereira, 2001). Tendo em vista que os problemas de agressividade extrapolam fronteiras físicas entre os países, esta temática preocupa, de modo geral, todos os educadores, com a tendência a se colocar observadores, professores e outros elementos da escola para fiscalizar tais atividades. No entanto, esta agressividade não é observada em crianças mais jovens e seria importante preservar estes momentos de crescimento individual de nossas crianças sem a intervenção ou fiscalização do adulto.

Como destacamos anteriormente, a família também assume seu papel de repressora toda vez que impede a criança de se expressar por meio dos gestos e da fala. Sendo sempre surpreendida por palavras e frases de negação como "não faça isso", "não mexa nisso", a família também próibe o acesso no que diz respeito à exploração do ambiente e não fornece respostas convincentes às suas indagações, o que leva a criança a se distanciar, cada vez mais, da descoberta através de suas próprias ações.

Para Faria (1997), a criança aprende e decifra o mundo quando brinca. Deste modo, apontamos o recreio escolar e as atividades que nele são realizadas como um espaço de interações que proporciona $o$ crescimento pessoal da criança pela vivência do lúdico. As atividades livres, realizadas durante o recreio, garantem a sua autonomia e possibilitam que ela organize, crie e reorganize seu espaço. Pedrosa, Carvalho e Hamburger (1996) identificaram em um grupo de crianças de dois e três anos de idade várias formas de organização enquanto brincavam livremente em uma escola. Verificaram neste estudo que as crianças, de maneira espontânea, se auto-organizam. No início das atividades, as ações eram individuais, caracterizadas como aleatórias e não apresentavam nenhum tipo de organização. Aos poucos, as ações evoluíram através de seqüências correlacionadas que se constituíram em configurações de (quase) equilíbrio dinâmico, identificadas como atratores. As autoras deste estudo, ao observarem as ações das crianças enquanto brincavam, identificaram duas configurações que persistiram durante alguns minutos e ocorreram com grande freqüência: corridas em círculo e imitação do comportamento de cachorro. Os resultados do estudo citado despertaram nosso interesse e nos levaram a investigar como novas formas de comportamento ou organização podem emergir em faixas etárias diferentes daquelas investigadas por Pedrosa et al. (1996). A partir dos resultados obtidos no trabalho citado, a primeira questão que norteia o presente estudo é: as formas de organização que emergem nas atividades livres de crianças de 4/5 anos são semelhantes àquelas que emergem nas atividades livres de crianças de $6 / 7$ anos de idade? 
A forma como as habilidades motoras se manifestam no ser humano tem sido foco de interesse de pesquisadores da área de estudo do comportamento motor que buscam identificar as mudanças que ocorrem ao longo da vida. Estas mudanças podem significar a busca de algo que é desconhecido, novo para o sujeito e é isto que Assmam (1997) chama de aprendizagem. Esta aprendizagem não só ocorre em situação formal, especificamente preparada e organizada para tal fim, mas também em situações informais por meio da observação do comportamento dos pais, professores e principalmente dos pares do aprendiz. Isto nos leva à segunda questão que norteia o presente estudo: quais as possibilidades de aquisição de habilidades motoras nas brincadeiras livres na escola por crianças de 4/5 anos e 6/7 anos de idade? Acreditamos que o processo de aprendizagem de habilidades motoras e verbais pode ocorrer em qualquer segmento da sociedade, como, por exemplo, na família, na escola, no clube e na igreja.

Estudos acerca das atividades livres das crianças na escola ainda são bastante escassos. Acreditamos que estas atividades trazem excelentes benefícios para o desenvolvimento harmonioso das várias facetas do comportamento humano e consideramos necessário revisitar esta temática à luz de novas abordagens holísticas de investigação. Deste modo, nos propusemos a identificar, neste estudo, as formas de organização e autoorganização na realização de atividades livres de crianças de diferentes faixas etárias e as possibilidades de aquisição de habilidades motoras neste contexto.

\section{A NATUREZA DAS MUDANÇAS NO COMPORTAMENTO MOTOR}

Ao longo do curso do desenvolvimento humano ocorrem mudanças estruturais e funcionais nos aspectos cognitivo, afetivo e motor. Essas mudanças têm sido foco de investigação dos pesquisadores do comportamento motor que buscam desvendar as transformações motoras ao longo da vida. O desenvolvimento motor é caracterizado como um processo seqüencial e contínuo de transformações que obedecem a uma progressão de movimentos simples para movimentos mais complexos e mais ordenados (Clark, Whitall, 1989). Como explicar esse processo de desenvolvimento?

Segundo Clark e Whitall (1989), das teorias que foram elaboradas para explicar o desenvolvimento e principalmente o desenvolvimento motor, a Teoria dos Sistemas Dinâmicos ofereceria a possibilidade de unificação das teorias do desenvolvimento do comportamento, pois 
integraria todos os níveis de análise pertinentes ao desenvolvimento motor. De fato, a literatura é rica em estudos que se apóiam na Teoria dos Sistemas Dinâmicos para explicar o controle e a coordenação dos movimentos bem como as mudanças que ocorrem no comportamento motor durante a vida. De acordo com esta abordagem, o ser humano passa a ser visto como um sistema complexo e dinâmico que interage, troca energia e informação com o meio externo (Pellegrini, Gonzales, 1997).

Segundo Thelen (1993), a teoria dinâmica rompe com a visão das teorias precedentes ao afirmar que o corpo não é visto de forma manipulativa. Para Thelen, os princípios da teoria dos sistemas dinâmicos permitem esclarecer como as formas de comportamento podem emergir de maneira auto-organizada sem que haja a necessidade de um elemento centralizador ou de um programa preestabelecido com a função de controlar as ações motoras. Esta nova concepção dinâmica olha para o corpo como um sistema físico que é capaz de gerar padrões de cooperação e competição entre elementos que participam do processo. Novas formas de comportamento manifestam-se devido à cooperação e interação dos múltiplos elementos dentro do contexto da tarefa (Thelen, Ulrich, 1991).

A Teoria dos Sistemas Dinâmicos não se aplica somente a um sistema formado por um organismo e seu ambiente, mas pode ser identificada também nas relações interpessoais, em sistemas que envolvam dois ou mais indivíduos. Schmidt e O'Brien (1997) investigaram a coordenação entre duas pessoas em uma tarefa laboratorial. Participaram deste estudo 10 duplas, sendo 6 pares constituídos de homens e mulheres e 4 pares formado somente por mulheres, estudantes do curso de psicologia com idades entre 18 e 30 anos. Os pares foram formados randomicamente e permaneceram sentados um ao lado do outro durante o experimento. As cadeiras nas quais eles se sentavam eram colocadas lado a lado, separadas por uma divisória. Enquanto um indivíduo manipulava um pêndulo de $0,32 \mathrm{~m}$ de comprimento o outro manipulava um de $0,62 \mathrm{~m}$. Os participantes realizaram a tarefa de modo que nos 12 minutos iniciais permaneciam com a visão sempre voltada para a frente e nos 12 minutos finais os participantes podiam olhar um para o outro ao manipularem o pêndulo. Após análise dos dados ficou evidente para os investigadores que nos 12 minutos finais os participantes passaram a interferir na ação motora um do outro, ou seja, sincronizaram seus movimentos naturalmente.

Podemos observar a influência de um indivíduo agindo no comportamento do outro em nosso dia a dia, como, por exemplo, em uma caminhada realizada por duas pessoas. Ao iniciarem suas atividades, elas apresentam comportamentos diferenciados, mas com o passar do tempo esses comportamentos vão se ajustando espontaneamente na medida em 
que um vai interferindo no comportamento do outro. Esse comportamento, que emerge da relação entre os dois indivíduos, é fruto do processo de auto-organização.

Em resumo, o organismo evolui de um estado menos organizado para um sistema mais organizado mediante o processo de autoorganização, cujos subsistemas muscular, cárdio-respiratório, nervoso e outros se reúnem em cooperação. Os subsistemas se auto-organizam para levar o organismo a um estado de prontidão para que novos comportamentos possam emergir por meio do processo de autoorganização. Vejamos a seguir no que consiste a auto-organização.

Debrun (1996) afirma que uma organização ou forma é autoorganizada quando se produz a si própria, não surge no vazio, mas acontece devido às relações entre os elementos que constituem o sistema. Para ele, só existe auto-organização quando os elementos que estão envolvidos no sistema cooperam (e competem) entre si, garantindo assim a manutenção da forma já existente ou o aparecimento de uma nova forma.

O termo auto-organização, de imediato, nos proporciona a idéia de organização (de algo que seja organizado), ou seja, que apresenta ordem, mas para que essa ordem se estabeleça é necessário haver interação por parte dos elementos que participam do processo. Para Souza (1997), a organização de um sistema refere-se ao padrão característico de interação dos elementos do sistema. Na organização, os elementos se juntam de forma sistemática e cooperativa e as relações existentes entre os elementos que participam do sistema garantem a unidade do mesmo (Pellegrini, 1996).

É importante ressaltar que a constituição dos organismos vivos não se estabelece somente pela quantidade de elementos que constituem o sistema mas, também, pela heterogeneidade encontrada em todos os níveis de organização, das estruturas moleculares aos componentes de respiração, cognição e outros. O ser humano, durante o ciclo vital, aumenta gradativamente seu grau de complexidade e ordem. Segundo Souza (1998), não é fácil definir e nem tampouco medir a complexidade de um sistema e propõe ser a complexidade um conjunto das relações que existem entre as partes constituintes de um sistema.

O processo de auto-organização origina-se, principalmente, a partir dele próprio, possuindo em si um aspecto criador, fruto das interações estabelecidas entre as partes ou elementos que participam dele. Isso significa dizer que o processo de auto-organização não é determinado por regras ou leis preestabelecidas, mas sim pelas relações estabelecidas entre os elementos que compõem o sistema. Os elementos que constituem o sistema apresentam predisposição para relacionar-se parcial ou totalmente. 
Uma organização surge quando os elementos dependentes de um sistema passam a cooperar entre si, adquirindo a capacidade de estabelecer, espontaneamente, novas formas de organização do sistema. Podemos observar esta predisposição para engajar-se quando as crianças brincam livremente. As ações iniciais não apresentam nenhuma relação, mas, aos poucos, o sistema passa a ser regido por relações dinâmicas que evoluem para novas formas de comportamento distintas e mais auto-organizadas.

Em um processo de auto-organização um dos elementos que compõe o sistema, de certa forma, define a preferência do organismo por certos padrões de comportamento, resultando da ação cooperativa dos subsistemas em um contexto particular. A auto-organização é um processo que ocorre sob certas condições físicas e termodinâmicas, cujos elementos interagem formando uma unidade (Thelen, Ulrich, 1991). Segundo Morin (1996), as interações exprimem o conjunto das relações, ações e retroações que se efetuam e se tecem em um sistema. Para que ocorra autoorganização é necessário que haja interação que se evidencia pelo encontro dos elementos no sistema e, essas interações, que são decorrentes do processo, são geradoras de formas e organização.

Este processo de auto-organização, que é o resultado das relações estabelecidas pelos elementos que constituem o sistema, foi detectado por Pedrosa e Carvalho (1995) com base em análise qualitativa de episódios lúdicos que mostraram a ocorrência de brincadeiras compartilhadas sem a sugestão ou a interferência do adulto, em crianças com menos de dois anos de idade. De acordo com as autoras, crianças bem novas constroem suas brincadeiras tendo por base as ações de seus pares, ajustando-se a eles. Embora a relação entre o professor e o aluno seja o foco de atenção da maioria dos estudos a respeito do desenvolvimento, o estudo citado deixa clara a importância da relação aluno-aluno no contexto escolar.

Posteriormente, Pedrosa, Carvalho e Hamburger (1996) observaram os movimentos produzidos espontaneamente por crianças de dois e três anos de idade que freqüentavam uma determinada creche. A análise ocorreu a partir de movimentos livres, espontâneos e em desordem que evoluíram até se constituírem em configurações de equilíbrio dinâmico. Participaram do estudo sete crianças que foram colocadas em uma sala que media $5 \mathrm{~m} \times 5 \mathrm{~m}$, livre de qualquer obstáculo e sem a presença de brinquedos, pois encontravam-se todos guardados no armário. Nesse estudo, às crianças foi garantida a liberdade de expressão e elas foram incentivadas a se movimentarem livremente pelo espaço. Todas as ações das crianças foram filmadas por um adulto e registradas em vídeo. Segundo relato das autoras, as crianças entram na sala e começam a correr de um lado para o outro fazendo muito barulho. As relações surgem 
espontaneamente e, por meio da ação individual de cada criança e da interação entre elas, o sistema se auto-organiza.

As autoras perceberam também que as crianças estabeleciam entre si relações enquanto brincavam, relações estas identificadas como campo de interação. A construção do espaço interacional proporcionou às crianças troca de informações. Além do campo de interação, as autoras destacam ainda a orientação da atenção como o primeiro momento que leva à organização. Essa orientação ocorre a partir do momento em que a criança apresenta predisposição para engajar-se nas atividades ou até mesmo monitorar as ações de outras crianças. Uma outra característica que surge é a atribuição compartilhada de significado, ou seja, quando duas ou mais crianças agem conjuntamente, suas ações podem gerar um novo significado em suas relações. Por fim, a última característica apontada pelas autoras foi a da persistência de significado que está relacionada com o período de tempo que o sistema persiste em uma determinada forma.

Pedrosa et al. (1996) observaram que, como fruto da espontaneidade em suas ações motoras, as crianças se auto-organizaram. Suas ações motoras, que inicialmente se caracterizavam como desorganizadas, evoluíram para formas organizadas, nas quais as ações individuais transformam-se em ações coletivas. As autoras tiveram também a preocupação de caracterizar as formas de organização apresentada pelas crianças de dois e três anos de idade. Puderam observar, por intermédio das imagens registradas em vídeo, diversas formas de organização durante as brincadeiras realizadas pelas crianças, como corridas em linha reta na horizontal; corridas em círculo; desenhos de caracol, representando as crianças rodopiando (sem muita persistência); corridas no sentido transversal; representação de cachorros e outras. Durante a análise dos dados, observaram duas formas que persistiram por um bom tempo: as corridas em círculo e a representação de cachorros. As formas que emergiram durante as brincadeiras das crianças permitiram caracterizar o sistema como auto-organizado, pois as estratégias adotadas para organizar o ambiente surgiram espontaneamente entre elas. Para Assman (1997), a emergência de formas é caracterizada pelas mudanças que ocorrem na estrutura de um sistema, originando, a partir delas, bifurcações, flutuações e inovações comportamentais. A aprendizagem de habilidades motoras pode ser vista como a emergência de formas no curso do desenvolvimento humano. Ao analisar os resultados encontrados por Pedrosa et al. (1996) pudemos constatar que as crianças, enquanto realizavam suas atividades, eram capazes de aprender habilidades motoras umas com as outras, e esta aprendizagem só foi possível devido às relações estabelecidas entre elas. 


\section{APRENDIZAGEM DE HABILIDADES MOTORAS}

O movimento é o nosso meio de inserção no mundo. Para que possamos caminhar, andar, correr, escrever, jogar necessitamos do amadurecimento e do refinamento de nossas habilidades motoras básicas. É por intermédio do movimento que conseguimos manter relações com o meio que nos cerca e com todas as espécies existentes no reino animal.

Para Thomaz (1999), o processo que desencadeia a aprendizagem de habilidades motoras nas crianças é fascinante. Para ele, um longo caminho é percorrido por elas no intuito de aprender uma tarefa motora, como, por exemplo, arremessar uma bola ao cesto, controlar os botões de um vídeo game ou ainda chutar uma bola na direção do gol. Este autor afirma que alguns estudos têm mostrado diferenças na execução de habilidades motoras realizadas por meninos e meninas, e aponta o meio ambiente e os traços culturais como fatores relevantes para que essa diferença aconteça. Comprovou estas evidências quando selecionou várias habilidades, em um total de 20, e verificou por meio delas que os meninos se destacavam em atividades que exigiam força, enquanto as meninas se sobressaíam em atividades que exigiam flexibilidade.

Em específico, Jacquin (1979) afirma que a aprendizagem pode ser entendida como resultado da observação do aprendiz ao olhar alguém executando alguma ação motora e, logo em seguida, tenta reproduzir o gesto observado. Nesse caso, poderíamos dizer que a aprendizagem ocorreu por imitação. A criança ao observar outra criança passa a fazer comparações entre seus movimentos e os do seu parceiro (Oliveira, Rossetti-Oliveira, 1993). Este tipo de aprendizagem que acontece a partir da observação do outro foi sistematizado por Bandura (1977) ao propor a teoria da modelagem ou da aprendizagem social. Esta teoria aponta a utilização da demonstração ou de um modelo como facilitador da aprendizagem.

Existem evidências na literatura mostrando que em situações formais de aprendizagem, quando o professor estabelece as condições para que a aprendizagem ocorra, o modelo facilita a aquisição de habilidades motoras (Tonello, Pellegrini, 1998; Darido, 1991). Acreditamos porém que, em situações informais de aprendizagem, o par ou parceiro é o modelo na aquisição de habilidades motoras. A criança, enquanto brinca, observa as ações das demais que estão ao seu redor e, depois, tenta reproduzi-las. A aquisição de novas habilidades motoras ocorre devido às relações que estabelecem entre si. Acreditamos que a aprendizagem também pode ocorrer em situações em que a criança não necessita da presença de um modelo ou de um parceiro. Dessa forma ela aprende, também, quando 
brinca individualmente ao explorar seu próprio corpo e o ambiente que a circunda quando se encontra em movimento.

Assmann (1997) ressalta que o ato de aprender, seja motor, social ou institucional, é um processo auto-organizado que caminha ao encontro do novo. Os processos emergentes passam a adquirir dinâmica própria na medida em que vão surgindo bifurcações. Ressalta ainda que a aprendizagem é um processo constante de mudanças em nossas vidas. Para este autor, a possibilidade de aprender algo não se resume apenas em aprender coisas, pois a aprendizagem acabaria sendo entendida como um aglomerado de informações. Não podemos atribuir à aprendizagem a noção de um amontoado sucessivo de coisas que vão se agrupando, mas deve-se entender a aprendizagem como uma teia ou rede de interações neuronais que são extremamente complexas e dinâmicas.

Para Tani (1999), essa busca do novo significa que o aprendiz está à procura de algo que ainda lhe é desconhecido e essa busca o levará a solucionar os problemas que o desafiam. É por intermédio da aprendizagem que o aprendiz vai desvendando, passa a passo, a busca do novo. Se diante da busca de soluções, frente a novos desafios, a criança apresentar dificuldades para resolvê-los, é necessário, nesse momento, a presença de um orientador que a conduzirá a uma aprendizagem mais eficaz.

Segundo Basso e Manoel (2001), vários trabalhos na área do comportamento motor têm procurado analisar qualitativamente os padrões fundamentais de movimentos executados por crianças durante a primeira infância. Para esses autores, ainda são bastante escassas as investigações que analisam as ações motoras que a criança realiza em ambientes que fazem parte do seu dia-a-dia, como, por exemplo, no parquinho, na escola, no clube e em outros ambientes. Esses autores acreditam que as crianças exploram com naturalidade diversas habilidades motoras quando brincam naturalmente, além de desenvolver habilidades sociais, lingüísticas e criativas.

\section{ATIVIDADES LIVRES DA CRIANÇA NA ESCOLA}

Um número variado de ações é observado durante a hora do recreio das crianças: gestos, falas, risadas, olhares, movimentos e acontecimentos. No início, observam-se movimentos realizados ao acaso, sem nenhum tipo de relação; uma agitação sem fim que permanece por um longo tempo. As brincadeiras estabelecidas pelas crianças começam a evoluir e a interação 
entre duas ou mais crianças dá significado a suas ações (Pedrosa et al., 1996).

A criança é um ser ativo e é por intermédio da brincadeira que ela se torna mais dinâmica, pois o brincar possibilita à criança monitorar suas próprias ações e dos seus pares. O brincar é uma realidade na vida da criança; "constitui um fato social e refere-se a determinada imagem de criança e brincadeira de uma comunidade ou grupo de pessoas específicas" (Wajskop, 1995, p. 65). Por meio da brincadeira, a criança passa a expressar seus desejos, medos, sentimentos e, com os conhecimentos adquiridos, o brincar passa a ser seu meio de inserção no mundo real. Wajskop (1995) acrescenta ainda que "A brincadeira compreende uma atitude mental e uma linguagem baseada na atribuição de significados diferentes aos objetos e à linguagem, comunicados e expressos por um sistema próprio de signos e sinais" (p. 65). O brincar expressa a forma como a criança reflete, ordena, planeja, organiza e reorganiza suas atitudes com base nas experiências vivenciadas (Deiderate, 1999).

Esta liberdade de expressão e de aprendizagem que o brincar proporciona à criança, própria de cada uma delas, aos poucos vai se expandindo. Ao ingressar na escola a criança tem a possibilidade de estabelecer novas relações, até então mantidas exclusivamente com a família e com as pessoas próximas a ela. Com o recreio, que é um período de atividade livre, a criança amplia suas potencialidades motoras e também sociais. O grande desafio enfrentado pelas crianças, nesta etapa de suas vidas, é a substituição do tempo livre que elas dispunham para brincar por regras estabelecidas pela escola, o que freqüentemente acaba levando as crianças a perderem a liberdade de expressão adquirida nos anos que antecederam sua entrada na escola.

Faria et al. (1997) afirmam que a criança ao ir para a escola já apresenta toda uma organização interna e a escola desconsidera essa organização. As atividades desenvolvidas de maneira espontânea pela criança passam a ser substituídas por regras, conteúdos, normas e objetivos estabelecidos pela escola. Estes autores afirmam que estas restrições atingem até mesmo o recreio que é o único horário em que a criança poderia colocar em prática toda a sua criatividade. Ressaltam, ainda, que o recreio, algum tempo atrás, foi caracterizado como um tempo improdutivo na escola, pois ele seria incapaz de promover a aprendizagem, ampliação e construção de conhecimentos. Ao analisarem a importância desta atividade para a criança, Pedrosa et al. (1996) e Faria et al. (1997) constataram que as atividades livres, realizadas durante o recreio escolar, têm se caracterizado como um espaço privilegiado de sociabilização, de troca de conhecimentos, onde a criança aprende e põe em prática todo seu potencial criativo. 
Poderíamos dizer que a principal característica das atividades livres é a liberdade e a independência que a criança tem para organizar o seu tempo livre para brincar, pois ela mesma direciona suas próprias ações. A criança sabe exatamente qual atitude tomar, pois sua espontaneidade lhe possibilita criar e recriar suas brincadeiras, sem que haja interferência de um professor ou de uma outra pessoa. $\mathrm{O}$ recreio proporciona à criança crescimento pessoal (Pedrosa et al., 1996). Poucos reconhecem no brincar a riqueza de possibilidades que esta atividade proporciona, pois a criança aprende e decifra o mundo brincando (Faria et al., 1997).

$\mathrm{O}$ ambiente do recreio, onde a criança brinca livremente, deve ser um lugar agradável e atrativo, pois ela acaba descobrindo a satisfação de realizar espontaneamente seus movimentos. A presença de material, na área de recreio, possibilita à criança transformar, destruir e reconstruir, pois ela altera com facilidade o seu espaço de jogos e brincadeiras (Faria et al., 1997). No entanto, o material não é necessário para que a brincadeira ocorra. É exatamente na ausência dele que a criança descobre o outro, o par, os colegas para brincar.

O envolvimento da criança em atividades livres, nas quais predomina a espontaneidade, faz com que seus movimentos fluam com mais naturalidade e ela só pára de brincar quando se sente cansada ou quando a atividade que está realizando não a satisfaz mais, levando-a a desistir ou abandonar tal atividade. Logo em seguida, pelo seu dinamismo, engaja-se em uma nova atividade. A não permanência por longo período em uma mesma atividade também pode ser observada nas atividades orientadas tanto pelos pais, quanto pelos professores na escola. Uma discordância entre o que é esperado pela criança e o que lhe é proposto ou imposto pelos adultos é o que na verdade acontece.

Para Haywood e Getchell (2001), o recreio e o playground são espaços privilegiados que possibilitam à criança manter contato com outras crianças, pois o brincar expõe a criança a situações de socialização. É importante ressaltar que a função do adulto neste processo é de facilitador e mediador e não de direcionador. É de responsabilidade dos pais e dos adultos encorajar a criança a conversar com outras crianças, interagir, compartilhar e cooperar.

Partindo do pressuposto de que as crianças se auto-organizam em suas atividades livres na escola, o presente estudo teve como objetivos identificar as formas de organização apresentadas por crianças de duas faixas etárias, sem a utilização de brinquedos ou de qualquer equipamento e identificar situações em que a aquisição de habilidades motoras ocorre no desenrolar das atividades livres da criança na escola. 


\section{MÉTODO}

\section{Participantes}

Participaram deste estudo 24 crianças com idades entre 4 e 7 anos. As crianças foram divididas em dois grupos: A (4/5 anos) e B (6/7 anos). No grupo A tivemos a participação de 8 meninas e 4 meninos e no grupo B participaram 6 meninas e 6 meninos.

\section{Procedimentos}

Duas câmeras filmadoras registraram ações das crianças por 15 minutos. As câmeras foram fixadas com antecedência em um lugar previamente estabelecido que nos permitiu visualizar todo o espaço a ser filmado. Esta medida foi tomada no intuito de evitar que as crianças se sentissem intimidadas com a presença das câmeras, ou que se sentissem atraídas por elas. Para facilitar a observação e análise das imagens, as câmeras foram identificadas de Câmera 1 (C1) e Câmera 2 (C2). A Figura 1(a) apresenta uma representação esquematizada do local e do equipamento para a coleta de dados. A coleta de dados foi realizada na quadra poliesportiva da escola freqüentada pelas crianças, a qual media $20 \mathrm{~m} \times 16 \mathrm{~m}$. Utilizamos aproximadamente $56 \mathrm{~m}^{2}$ dessa área, livre de qualquer obstáculo, com exceção dos cones que serviram para delimitá-la. As câmeras possuíam funções específicas: enquanto a $\mathrm{C} 1$ nos fornecia as imagens de toda a área que estava sendo filmada, a C2 registrava as imagens do centro ao final da área em estudo, além de nos possibilitar a gravação de sons produzidos pelas crianças como falas e gritos.

Ao chegarem ao local da coleta, todas as crianças foram orientadas para brincar livremente, mas para não sair do espaço que estava demarcado. Elas brincavam sem a utilização de brinquedos, sem a presença do professor de educação física, do professor de sala de aula ou qualquer outra pessoa. Para facilitar a obtenção das imagens, contamos com um operador de câmera que fez o registro em fita das ações das crianças durante a realização das brincadeiras. As duas câmeras eram acionadas com antecedência pelo operador de vídeo. Ao completar o tempo previsto para filmagem, o operador esperava a retirada de todas as crianças do local para poder desligar todo o equipamento. 


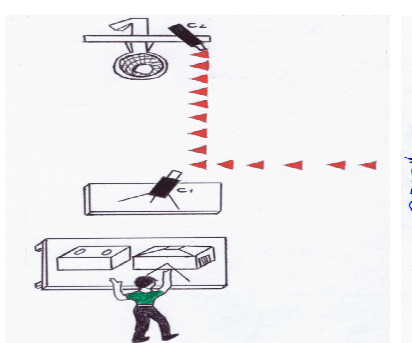

(a)

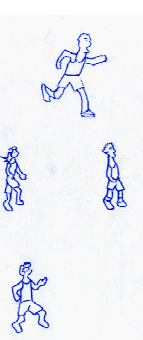

s

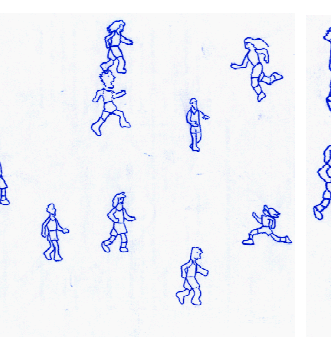

(b)

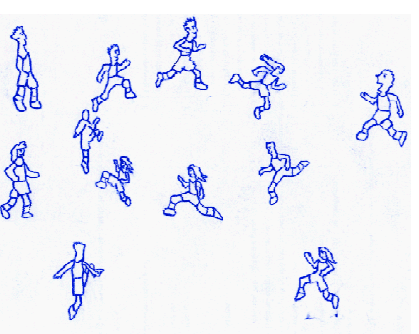

(c)

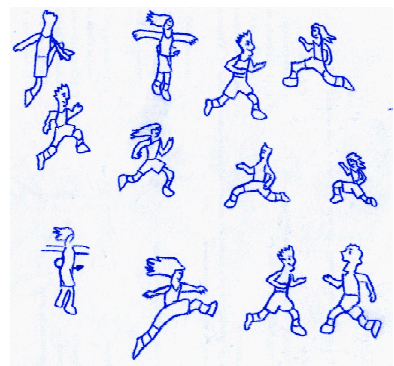

(d)

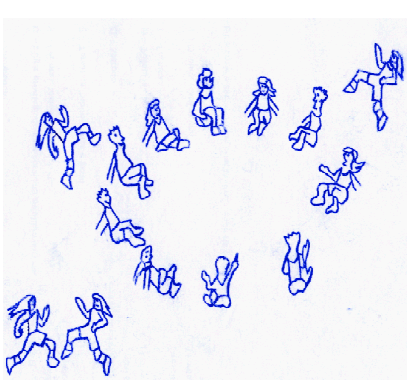

(e)

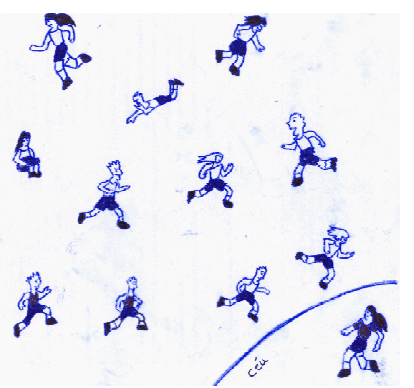

(f)

Figura 1 - a) Representação esquematizada do local e equipamento para a coleta de dados; b) Momento da chegada das crianças dos dois grupos no local da coleta de dados marcando o início das atividades; c) Dispersão das crianças e o aparecimento de diversas formas identificadas no grupo A; d) Dispersão das crianças e o aparecimento de diversas formas identificadas no grupo B; e) Representação esquemática da brincadeira do corre cotia desenvolvida pelas crianças do grupo A; f) Representação esquemática da brincadeira do pega-pega desenvolvida pelas crianças do grupo B.

As filmagens foram realizadas durante três dias alternados, com intervalos de $48 \mathrm{~h}$ de uma filmagem para a outra. Esta medida foi adotada no intuito de facilitar a identificação das estratégias de organização apresentadas pelas crianças, assim como as possibilidades de aprendizagem que estariam presentes. Os dois grupos receberam as mesmas informações para as três sessões de filmagem. Para a identificação e análise das formas de organização que emergiam espontaneamente durante as atividades das crianças, utilizamos as imagens obtidas nos 15 segundos iniciais de cada minuto ao longo dos 15 minutos de cada filmagem. Consideramos como emergência de formas as representações geométricas como retas, círculos, triângulos e outras que apareceram no decorrer da análise pelo menos em dois eventos seguidos, o que indicava consistência no padrão. A codificação dos registros foi feita por meio da identificação e registro gráfico das formas de organização apresentadas pelas crianças e das atividades físicas realizadas por elas. Para a 
identificação de aprendizagem de habilidades motoras foram analisados os 15 minutos de cada filmagem com base no seguinte critério: 1) Ações individuais - quando a criança explorava o seu próprio corpo em movimento e o ambiente à sua volta; 2) Aprendizagem por imitação ou modelo - quando a criança observava o que uma outra criança estava fazendo (atenção dirigida) e depois tentava imitá-la; 3) A busca de um parceiro - quando a criança ia ao encontro de outra para que juntas pudessem executar uma tarefa motora e ela orientava o parceiro sobre a tarefa a ser realizada.

\section{RESULTADOS}

O primeiro momento a ser destacado é o início do processo, ou seja, o instante em que as crianças chegam ao local da coleta. Algumas sempre muito agitadas, conversando e correndo de um lado para outro o tempo todo, enquanto outras chegavam calmamente. Caracterizamos este momento como o ponto de partida das atividades livres das crianças. Ver Fig. 1(b).

Com base nas imagens analisadas, verificamos que as crianças de 4/5 anos de idade, ao longo do desenvolvimento de suas atividades, apresentavam predisposição para permanecerem juntas. No início, sempre bem cautelosas, paravam por alguns segundos, observavam o ambiente e em seguida passavam a explorá-lo. Essa atitude das crianças, de sempre observar antes de agir, foi detectada nas três sessões das atividades filmadas. Somente após o reconhecimento da área reservada para a realização das atividades é que as ações das crianças foram emergindo.

Embora as crianças apresentassem todas as condições para se deslocarem no espaço todo, elas sempre procuravam respeitar a área destinada pelo experimentador para o brincar. Esta preocupação de acatar as dimensões estabelecidas foi apresentada principalmente pelas crianças do grupo A, com $4 / 5$ anos, o que nos faz acreditar que as crianças nesta faixa etária já apresentam uma boa noção de espaço. O comportamento inicial desse grupo de crianças foi de conferir os cones que eram utilizados para isolar a área que brincavam. Isso ocorreu espontaneamente, pois uma das crianças tomou a iniciativa de contar os cones e logo em seguida todas as demais crianças aderiram com naturalidade à atividade formando uma fila. A contagem dos cones era feita em alguns momentos em ordem crescente, em outros em ordem decrescente e às vezes sem ordem alguma. Todos esses acontecimentos foram registrados nos minutos iniciais da filmagem das atividades das crianças de $4 / 5$ anos. 
Em seguida, as crianças agrupavam-se em um grande círculo, todas sentadas no chão, ficando cerca de dois minutos conversando, levando-nos a acreditar que dali partiriam as idéias de como ocupar o local destinado a elas. Vale ressaltar que esse encontro das crianças ocorreu em diversos momentos da seqüência de atividades. É importante destacar também que a partir desta formação em círculo as atividades foram tomando novos rumos. Mas para que isso acontecesse, foi necessário que houvesse uma ruptura do grupo, ou seja, que houvesse uma quebra das relações mantidas até aquele momento, acarretando a dispersão de todos os participantes do grupo (Fig.1c). Enquanto algumas crianças corriam em vários sentidos, como corridas em diagonal, corridas em linha reta ou corridas em círculo, outras simplesmente caminhavam de um lado para o outro ou permaneciam sentadas, talvez por não se sentirem atraídas pela atividade daquele instante. Todos esses acontecimentos sempre eram acompanhados de muita conversa, gritos e gestos. Outro fato que merece destaque, após o grupo ser desfeito, é o surgimento de pequenos grupos, ora com a participação de duas, três, ou quatro crianças e às vezes todas as crianças, dependendo do tipo da atividade que era proposta por elas. A integração, a cooperação e a dispersão foram elementos marcantes durante todo o desenvolvimento das atividades realizadas por esse grupo de crianças.

$\mathrm{O}$ ato de integrar-se e dispersar-se, espontâneo e natural de cada criança, garantia a ela o direito de interromper sua participação no que estava fazendo, a qualquer momento, ou inserir-se em novas formas de organização. A busca de novas interações ocorria toda vez que ela não se sentia mais atraída pela atividade, e sua participação, em algumas atividades, acontecia de forma bastante rápida. Observamos também que, mesmo antes de garantir sua participação em uma outra atividade, as crianças sempre paravam, observavam e em seguida tomavam a decisão quanto à sua participação ou não na ação do grupo.

Quanto às crianças de 6/7 anos, elas apresentavam desde o início um comportamento mais agitado do que aquele apresentado pelas crianças de 4/5 anos. Desde a sua chegada na área de filmagem até o seu final, movimentavam-se incessantemente. Apontamos aqui a grande diferença entre os grupos no que diz respeito às estratégias de organização do espaço. As crianças do grupo B, com idades superiores às do grupo A, já apresentavam indícios de preferência por determinados companheiros, ou seja, algumas buscavam brincar com os colegas com quem tinham mais afinidade. Como conseqüência surgiram vários subgrupos, sendo bem visível a divisão entre meninos e meninas. Em raríssimas exceções, todas as crianças participavam de uma mesma atividade. Percebemos então que este grupo de crianças já apresenta uma certa autonomia; as crianças escolhiam 
com quem desejavam brincar e qual a atividade em que se sentiam mais à vontade para se engajar.

Quanto às formas iniciais de organização que surgiram e que perduraram durante a realização das atividades possibilitaram às crianças um inter-relacionamento, sempre explorando as mesmas corridas do grupo A, ou seja, corridas em linha reta, corridas em diagonal e corridas em círculo. Detectamos também algumas alterações, no que diz respeito a execução de uma ação motora, com a combinação de duas habilidades como correr e saltitar, correr e girar (Fig.1d). Essas modificações na execução das habilidades motoras acontecem em razão da criança apresentar um certo grau de controle de suas ações motoras.

As brincadeiras dos dois grupos surgiram de maneira sempre espontânea. As crianças do grupo A, de 4/5 anos, organizaram entre elas a brincadeira do corre cotia (Fig.1e), uma atividade bem familiar e de grande freqüência nas aulas de Educação Física. A brincadeira é desenvolvida da seguinte forma: as crianças ficam sentadas no chão formando um círculo e um dos participantes corre em volta do grupo com uma bola na mão. Enquanto ele corre, o grupo canta esta musiquinha "corre cotia na casa da tia ... lencinho na mão ... moça bonita do meu coração é 1, 2, 3 ... apague a luz". Ao término da música, as crianças permanecem sentadas e abaixam a cabeça, para que o participante coloque a bola atrás de um dos coleguinhas que está sentado. Em seguida, a criança que está com a bola atrás dela, agarra a bola e corre em sentido contrário ao do participante que colocou a bola atrás dela, tendo como meta chegar novamente ao seu lugar antes que o outro o faça. Caso isso não ocorra, a criança que estiver com a bola, deverá dar prosseguimento à brincadeira reiniciando o canto.

No presente estudo tivemos a preocupação de investigar como é que um grupo de crianças poderia organizar suas atividades sem que fosse necessária a presença de algum tipo de material. Na brincadeira desenvolvida por estas crianças, é extremamente necessária a presença do material, no caso uma bola. Mesmo na sua ausência a brincadeira aconteceu. Esta atividade surgiu quando duas meninas brincavam separadamente, de corre cotia, enquanto as outras crianças corriam, incansavelmente, em todas as direções. A brincadeira, que no início era praticada por apenas duas meninas, passou a contar com um número maior de participantes. A brincadeira foi desenvolvida pelas crianças de forma convencional, tendo como ponto de partida a determinação das condições para que a brincadeira pudesse acontecer. A bola era de papel, encontrado na área de coleta e confeccionada pelas próprias crianças. $\mathrm{O}$ ponto de partida, estabelecido pelas duas meninas, e o engajamento das 
demais crianças tornaram-se elementos fundamentais para que o sistema se auto-organizasse.

No grupo B, o pega-pega (Fig.1f) foi a primeira atividade coletiva que surgiu entre os participantes. Meio ao corre-corre surge uma menina que propõe a brincadeira. A participação na brincadeira vai tendo, aos poucos, a adesão de outras crianças e o seu engajamento, assim como foi observado no corre cotia com as crianças de $4 / 5$ anos, acontece naturalmente. A brincadeira do pega-pega é uma atividade bastante explorada nas aulas de Educação Física, e de grande aceitação pelas crianças por apresentar grande movimentação.

Como toda brincadeira, e esta não foge à regra, são necessárias algumas condições para que ela aconteça, e, neste caso, as próprias crianças as definiram. Enquanto uma corria, tentando fugir do pegador, as outras se protegiam ficando de cócoras, sentadas ou deitadas no chão, ou iam para o céu, local onde se sentiam totalmente protegidas do pegador. Esta brincadeira persistiu por um longo período de tempo, até o momento em que foi abolida, dando oportunidade às crianças de optar por novas formas de interação. Vale destacar nesta brincadeira a liberdade de expressão apresentada pelas crianças do grupo B. Durante a realização dessa atividade, algumas crianças tentavam atrair a atenção do pegador, ora acenando, ora chamando pelo nome. O corre-corre era inesgotável, ocasionando diversas formas de corrida, ou seja, em diagonal, em linha reta e em círculo, além do aparecimento de várias ações motoras ao longo da brincadeira.

Pudemos observar que os grupos A e B apresentaram formas distintas de organização das atividades. Enquanto as crianças de 4/5 anos se agrupavam e sentavam em círculos, levando bastante tempo conversando até decidirem o que iriam fazer, na grande maioria das vezes, elas procuravam realizar suas atividades coletivamente. Por outro lado, as crianças de 6/7 anos já apresentavam preferência por alguns colegas, com a formação de subgrupos como duplas, trios, quartetos nos quais meninos e meninas brincam separadamente. Em alguns casos, bastante isolados, participavam da mesma atividade, como no caso da brincadeira do pegapega.

As ações individuais e as relações mantidas entre as crianças dão forma à organização do sistema. As relações estabelecidas pelas crianças dos grupos A e B ocorriam de forma natural e espontânea; os grupos muitas vezes mostravam-se compactos, constituindo-se em um único sistema mas, inesperadamente, parece que ocorria uma grande explosão que levaria à dispersão de todo o grupo. Esta alternância entre os momentos de grande concentração das crianças e os de afastamento das 
atividades ocorreram com grande freqüência ao longo do tempo em que as atividades foram registradas em vídeo, o que nos leva a acreditar que o sistema permanecia em constante mudança, indicando que as crianças possuíam a capacidade de organizar e reorganizar suas atividades enquanto brincavam.

A criança, não se satisfazendo com formas de organização voltadas para ela própria, passa a procurar novas formas de organização, ocorrendo, neste momento, a transição de uma organização individual para uma organização grupal. Na medida em que a criança tem sua participação garantida no grupo, ela passa a estabelecer novas relações e, nesse momento, a aprendizagem se manifesta. As crianças aprendiam umas com as outras por meio das suas próprias ações.

\section{DISCUSSÃO}

Nossa primeira questão de estudo foi verificar as diferenças nas formas de organização das atividades livres na escola entre as crianças de $4 / 5$ anos e as de 6/7 anos de idade. Pudemos observar o desenvolvimento de cada grupo ao longo das três sessões. No início das atividades, assim como visto por Pedrosa et al. (1996), observamos que as relações estabelecidas pelas crianças aconteciam de maneira natural e espontânea. Podemos caracterizar também estes movimentos iniciais, apresentados pelas crianças, como aleatórios, isto é, sem padrões que fossem identificáveis. $\mathrm{O}$ início do processo foi marcado pelo encontro de várias crianças dispersas, sem que houvesse qualquer tipo de conexão entre elas. Essas crianças passaram a se agrupar e em seguida, após se dispersarem, estavam livres para estabelecer novas conexões.

Para Debrun (1996), este começo (início) é extremamente importante, pois ocorre uma ruptura com o passado, com o contexto, tornando o sistema mais independente. Verificamos neste estudo, que a partir do encontro das crianças, o sistema passou a ser regido por relações dinâmicas que evoluíram para novas formas de comportamentos distintos e mais auto-organizados. Essas relações surgiram pelo fato das crianças apresentarem predisposição para engajarem-se. As formas de organização que emergiram foram identificadas pelas mudanças que ocorreram na estrutura do sistema (Asmann, 1997).

Por intermédio das imagens registradas em vídeo, observamos algumas formas de organização no momento em que as brincadeiras aconteciam, como as corridas em linha reta, corridas em diagonal e corridas em círculo. Algumas destas formas permaneciam por determinado período 
de tempo, não chegando a um minuto. Este tempo só foi modificado quando as crianças do grupo B propuseram a brincadeira do pega-pega, que durou, aproximadamente, sete minutos. As formas que emergiram espontaneamente garantiram a organização do sistema e, a partir delas, as crianças puderam estabelecer entre elas diversas relações, dando o direito a cada uma de decidir em que tipo de organização iria participar.

Entre as crianças de $4 / 5$ anos a forma que mais persistiu foi a corrida em círculo, devido ao surgimento da brincadeira do corre cotia, enquanto entre as crianças de $6 / 7$ anos, as corridas, já identificadas anteriormente, estiveram mais presentes devido à brincadeira do pegapega, o que lhes dava a possibilidade de alterar as formas da corrida, variando entre um único pé, correr e girar, entre outras. As configurações, ou formas, encontradas neste estudo são semelhantes às identificadas por Pedrosa et al. (1996) quando investigaram o comportamento de crianças de 2 e 3 anos enquanto brincavam em uma creche. Os dados nos mostraram que os dois grupos apresentaram as mesmas configurações, com exceção da combinação de elementos utilizados somente pelas crianças do grupo B. Essa combinação de movimentos acontece devido à grande vivência de experiências motoras que essas crianças mais velhas possuem.

Como já mencionado anteriormente, tínhamos a intenção de investigar as formas de organização apresentadas por estes dois grupos, assim como verificar as possibilidades de aprendizagem de habilidades motoras ao brincarem livremente. Definimos, a priori, as condições em que a aprendizagem de habilidades motoras pudesse ocorrer enquanto as crianças brincavam. A primeira forma de aprendizagem que propusemos diz respeito ao aprender por si só. O segundo tipo de aprendizagem ocorre quando a criança observa a ação da outra e em seguida tenta reproduzi-la. E uma terceira forma de aprendizagem ocorre quando necessita do auxílio de uma outra criança para que juntas executem uma habilidade motora nova.

Detectamos na análise dos dois grupos, A e B, a presença de algumas habilidades motoras como cambalhotas, correr, saltar, pular, girar e rolar. A habilidade do saltar, executada pelas crianças do grupo B, apresentou algumas variações em sua execução como pular em um único pé, com os dois pés (lembrando o salto do sapo), alternando o salto ora com o pé esquerdo ora com o direito. Outra variação apresentada por esse grupo é o pulo parafuso, que consiste em dar um salto no sentido vertical e assim que uma certa altura é atingida é realizado um giro no ar. Essas combinações de movimento, apresentadas por essas crianças, são características dessa fase. Para Damiani e Barros (1992), a criança por volta dos 6 anos de idade melhora sua coordenação e, conseqüentemente, passa a 
executar seus movimentos com mais eficiência. Para Schmidt (1992), essas mudanças ocorrem em razão da prática, pois habilidades motoras são desenvolvidas e modificadas com a prática que ocorre ao longo do tempo e, para que sejam executadas com precisão, é necessário que seja desenvolvido um conjunto de mecanismos de controle motor. Essas variações, na forma de executar uma ação motora, estavam presentes no comportamento do grupo A, evidentemente em menor proporção, pois as crianças de 4/5 anos ainda não apresentam um grande domínio de certas habilidades motoras.

As diferenças na execução de habilidades motoras entre meninos e meninas apontadas por Thomaz (1999) foram observadas também neste estudo. As meninas destacam-se em atividades que exigem grande flexibilidade, enquanto os meninos preferem atividades que envolvam força (Tani et al., 1988), como, por exemplo, as lutas. Em contrapartida, as crianças de $4 / 5$ anos preferem habilidades como correr, pular e saltar.

Após a identificação das formas de organização apresentadas pelos dois grupos, identificamos também três situações em que a aprendizagem se manifestou, o que nos levou a responder à segunda questão investigada neste estudo referente às possibilidades de aprendizagem de habilidades motoras nas atividades livres na escola. Observamos em alguns momentos, durante nossa análise, que existiam algumas crianças que às vezes se isolavam das outras, recusando-se a participar das atividades que estavam sendo realizadas pelas demais. Pudemos observar que este era um momento extremamente importante para aquela criança, pois, estando de fora, passava a observar e a registrar atenciosamente todos os acontecimentos. Nesse momento, reservado exclusivamente a ela, passava a estabelecer relações com o meio na qual estava inserida, além de descobrir e reconhecer os limites do próprio corpo.

Outro aspecto que levava a criança a se afastar das outras era o fato de não se sentir apta a executar uma determinada ação motora e, por não conseguir, acabava se isolando. Garrison et al. (1971) acreditam que este isolamento pode estar relacionado com a timidez, o que levaria a criança a se afastar da atividade. A criança, quando percebia que outra atividade estava sendo proposta, na qual se sentia mais à vontade para participar, era motivada a retornar ao grupo. Pudemos constatar que mesmo brincando sozinha a criança aprende, pois acaba pondo em prática todo o potencial criativo e imaginário. Este isolamento da criança pode ser explicado pelas restrições do organismo (próprias do organismo), pelo ambiente (fora do organismo) e pela tarefa (forma de executar uma ação motora) identificadas por Newell (1986). Para esse autor, as restrições estão relacionadas com as características que limitam a realização do movimento. 
O segundo momento, que nós registramos como forma de aprendizagem, diz respeito ao aprender uma ação motora quando a criança observava a habilidade motora que estava sendo executada por outra criança. Ficou evidente que esta outra forma de aprendizagem também esteve muito presente nas atividades analisadas. As crianças, freqüentemente, resgatavam das aulas de Educação Física algumas habilidades e começavam a praticá-las, e, logo em seguida, a maioria delas começava a observar o que uma outra estava fazendo e tentava imitá-la. É importante ressaltar que outra forma de reproduzir um gesto motor é buscada com freqüência na televisão. As crianças de $4 / 5$ anos procuravam imitar os gestos dos super-heróis, enquanto as crianças de 6/7 anos reproduziam os gestos dos atletas que naquela ocasião participavam dos Jogos Olímpicos de Sidney, dando ênfase, principalmente, ao judô. A aprendizagem, nesse contexto, pode ser vista como fruto das observações da criança ao perceber a ação motora de uma outra criança.

Em uma situação formal de aprendizagem, cabe ao professor estabelecer condições para que a aprendizagem ocorra e o modelo facilitaria a aquisição de habilidades motoras (Tonello, Pellegrini, 1998; Darido, 1991). Neste estudo, as crianças passaram a observar as ações motoras umas das outras enquanto brincavam e a aprendizagem ocorria a partir da observação do outro.

A terceira e última forma de aprendizagem que identificamos estava voltada para a execução de uma habilidade motora que precisava do auxílio de uma outra pessoa para que pudesse ser realizada. Nessa forma de aprendizagem ficou clara a orientação e a informação transmitidas pela criança a uma outra, durante a realização de uma habilidade motora, registrada, principalmente, nas atividades que exigiam equilíbrio (parada de mão), força (girar de mãos dadas) e flexibilidade (dar cambalhotas). A criança sempre que necessitava fazer uma habilidade motora, e não conseguia realizá-la sozinha, buscava um parceiro para que juntos pudessem executá-la. Observamos que essas formas de aprendizagem ocorreram devido às relações estabelecidas pelas crianças, quando passaram a explorar suas próprias ações e a monitorar as ações motoras das outras crianças.

Em resumo, em cada sessão de atividades foram identificadas brincadeiras que perduravam por certo período de tempo, algumas por poucos minutos, outras por períodos mais longos. As crianças menores, no início das atividades, sempre permaneciam juntas e conversavam por certo tempo e, logo em seguida, acabavam se dispersando. As crianças maiores sempre exploravam as atividades que envolviam as corridas. Por exemplo, a brincadeira do pega-pega foi observada em todas as sessões, inicialmente 
com a participação de um número pequeno de crianças, ocasionalmente, todas as crianças do grupo participavam dessa brincadeira. A brincadeira do corre cotia foi observada apenas em uma das sessões de atividades das crianças menores.

As habilidades motoras apontadas neste estudo foram utilizadas com freqüência pelas crianças dos dois grupos. Nas três sessões, as ações motoras identificadas são freqüentemente trabalhadas nas aulas de Educação Física (cambalhotas, estrelinhas, saltar e outras) ou observadas nos programas televisivos, como, por exemplo, os movimentos de judô, presente nas atividades das crianças maiores. Durante a realização das atividades, algumas crianças preferiam isolar-se das demais; ficavam apenas observando o comportamento das outras. Este tipo de comportamento foi observado em todas as sessões em que os dados foram coletados. A criança, após alguns instantes, voltava a se reintegrar ao grupo.

\section{CONCLUSÃO}

O presente estudo buscou responder duas questões em específico. A primeira procurou verificar se existiam diferenças nas formas de organização das atividades livres na escola entre as crianças de $4 / 5$ anos e as de $6 / 7$ anos de idade e, a segunda, qual seria o potencial de aprendizagem de novas habilidades motoras nas atividades livres na escola. Os dados nos mostraram que os dois grupos apresentaram as mesmas configurações (ou formas) enquanto brincavam. A diferença encontrada, nas formas de um grupo para o outro, está na combinação de uma série de elementos utilizados pelas crianças do grupo B, isto é, à medida que iam explorando as corridas faziam algumas alterações como correr e saltar, correr em um único pé, correr e girar.

No que se refere à nossa segunda questão, observamos, durante a análise, três situações em que a aprendizagem ocorreu. A primeira estava relacionada com a aprendizagem por meio das ações individuais, ou seja, a criança quando brincava sozinha tinha a oportunidade de conhecer melhor o seu próprio corpo e o ambiente que a circundava. Na segunda forma de aprendizagem a criança observava a ação motora de uma outra criança e em seguida tentava reproduzi-la e, a terceira, quando necessitava da ajuda de um parceiro para que juntas executassem uma ação motora nova. Os dados nos sugerem que formas de auto-organização emergem espontaneamente enquanto as crianças brincam livremente. Essa atividade proporcionou a elas a ampliação de suas relações sociais. Enquanto 
brincavam, observamos que algumas vezes discutiam que brincadeira deveria ser realizada, manifestavam espírito de cooperação, trocavam e buscavam informações, experiências motoras e se sociabilizavam. As observações deste estudo apontaram que houve aprendizagem a partir das relações estabelecidas entre as crianças, quando passaram a explorar suas próprias ações e a orientar as ações motoras das outras crianças.

O recreio é um espaço privilegiado que oportuniza a criança a aprender e a demonstrar todo o seu potencial rico em imaginação. É necessário que a escola reconheça os benefícios que esta atividade pode proporcionar à criança. $\mathrm{O}$ recreio, que é um espaço para atividade livre, faz que a criança amplie suas potencialidades motoras e também sociais.

\section{REFERÊNCIAS BIBLIOGRÁFICAS}

ASSMANN, H. Reencantar a educação: rumo à sociedade aprendente. Petrópolis: Vozes, 1997.

BANDURA, A. Self-efficacy: toward a unifying theory of behavioral change. Psychological Review, v.84, p. 1215-91, 1977.

BASSO, L.; MANOEL, C.L.L. Observando o comportamento motor de crianças em movimentos livres na pré-escola: um estudo metodológico. In: II Congresso Internacional de Educação Física e Motricidade Humana e VIII Simpósio Paulista de Educação Física, 7. Anais... Rio Claro: Unesp, 2001, p. 151-152.

CLARK, J.E.; WHITALL, J. What is motor development? The lessons of history. Quest, v.41, p. 183-202, 1989.

DAMIANI, M.F.; BARROS, F.C. Desrespeito ao pobre? Renda familiar e desenvolvimento motor em crianças Pelotenses. Cadernos de Pesquisa. São Paulo, n.83, p.52-57, 1992.

DARIDO, S.C. Efeito de dois procedimentos de apresentação da informação na aprendizagem motora: demonstração e instrução. São Paulo, 1991. Dissertação (mestr.) Escola de Educação Física, Universidade de São Paulo, 114p.

DEBRUN, M. Pesquisa filosófica sobre o conceito de auto-organização. In: GONZALES, M.E.; DEBRUN, M.; PESSOA JÚNIOR, O. (orgs.). Autoorganização: estudos interdisciplinares em filosofia, ciências cognitivas e humanas e artes. Campinas: Unicamp, 1996. v.18, p.3-23. [Coleção CLE] 
DEIDERATE, L.M.F. Reflexões sobre as limitações da prática educativa que impedem e destroem o lúdico. [cited 21 junho 1999]. Disponível em: «http//www.pchelp.com.br/deside».

FARIA, E.L; PRADO, I.B.H.; NOGUEIRA, L.F. Lazer na escola: uma possibilidade de ampliação das vivências corporais lúdicas durante o recreio. Belo Horizonte: UFMG - Escola de Educação Física Centro de Estudos do Lazer e Recreação, 1997, p. 301-9.

GARRISON et al. Psicologia da criança: estudo geral e menticuloso do desenvolvimento e da socialização. São Paulo: Ibrasa, 1971.

HAYWOOD, K.M.; GETCHELL, N. Life span motor development. Champaign: Human Kinetics, 2001.

JACQUIN, J. O jogo, o brincar e a criança. Rio de Janeiro: Flamboyant, 1979.

KISHIMOTO, T.M. Jogo, brinquedo e brincadeira. In: MICOTTI, M.C.O. (org). Alfabetização: estudos e pesquisas. Rio Claro: Unesp, 1996. p. 99-117.

MARQUES, A.R.; NETO, C.; PEREIRA, B.O. Changes in school playground to reduce aggressive behaviour. Prevention and Control of Aggression and the Impact on its Victims. M. Martinez (ed.). Kluwer Academic/Plenum Publ., 2001.

MORIN, E. Ciência com consciência. Tradução M.D. Alexandre e M.A.S. Dória Bertrand Brasil, BCD União de Editores S.A., Rio de Janeiro, 1996.

MRECH, L.M. Além do sentido e do significado: a concepção psicanalítica da criança e do brincar. In: KISHIMOTO, T.M. (org). O brincar e suas teorias. São Paulo: Pioneira, 1998.

NEWELL, K.M. Constraints on the development of coordination. In: WADE, M.G.; WHITING, H.T.A . (eds.). Motor development in children: Aspects of coordination and control. Amsterdam: Martinus Nijhooff Publishers, 1986.

OLIVEIRA, Z.M.R. O valor da interação criança-criança em creches no desenvolvimento infantil. Cadernos de Pesquisa, São Paulo, n.87, p.62-70, nov. 1993. 
PEDROSA, M.I.; CARVALHO, A.M.A; HAMBURGER, A.I. Autoorganização em brincadeiras de crianças: de movimentos desordenados à realização de atratores. In: GONZALES, M.E.; DEBRUN, M.; PESSOA JÚNIOR, O. (orgs.). Auto-organização: estudos interdisciplinares em filosofia, ciências cognitivas e humanas e artes. Campinas: Unicamp. 1996. p.343-61. [Coleção CLE]

PEDROSA, M.I; CARVALHO, A.M. (1995). A interação social e a construção da brincadeira. Cadernos de Pesquisa, São Paulo, n.93, p.60-65, maio 1995.

PELLEGRINI, A.M. (1996). Auto-organização e desenvolvimento motor. In: GONZALES, M.E.; DEBRUN, M.; PESSOA JÚNIOR, O. (orgs.). Autoorganização: estudos interdisciplinares em filosofia, ciências cognitivas e humanas e artes. Campinas: Unicamp. p.299-318. [Coleção CLE]

PELLEGRINI, A.M.; GONZALES, M.E.Q. Em busca de harmonia no comportamento motor. In: PELLEGRINI, A.M. (org). Coletânea de estudos: comportamento motor I. São Paulo: Movimento. 1997. p.1-10.

SCHMIDT, R.A. Aprendizagem e performance motora: dos princípios à prática. Tradução: Flávia da Cunha Bastos, Olívia Cristina Ferreira Ribeiro. São Paulo: Movimento, 1992.

SCHMIDT, R.C.; O'BRIEN, B. Evaluanting the dynamics of unintended interpersonal coordination. Ecological Psychology, New Jersey, v.9, n.3, p. 189-206, 1997.

SOUZA, G.M. Ciência da complexidade e a morfogênese vegetal: uma abordagem da auto-organização. Campinas: CLE. 1997. [Texto elaborado para o Seminário CLE Auto-Organização]

SOUZA, G.M. A natureza das formas biológicas: a auto-organização e a cognição formadora. In: GONZALES, M.E.; BROENS, M.C. (orgs.). Encontro com as ciências cognitivas. Marília: Unesp. p.49-67, 1998.

TANI, G.; MANOEL, E.J.; KOKOBUN, E.; PROENÇA, J.E. de. Educação Física escolar: fundamentos de uma abordagem desenvolvimentista. São Paulo: EPU-EDUSP, 1988. 
TANI, G. Criança e movimento: o conceito de prática na aquisição de habilidades motoras. In: KREBS, R.J.; COPETTI, F.G.; BELTRAME, T.S.; USTRA, M. (orgs.). Perspectivas para o desenvolvimento infantil. Santa Maria: SIEC, p.121-138, 1999.

THELEN, E.; ULRICH, B.D. Hidden skills: A dynamic systems analysis of treadmill stepping during the first year. Monographs of the Society for Research in Child Development. Serial 223 (56), 1991.

THELEN, E. Timing and development dynamics in the acquisition of early motor skill. In: TURKEWITZ, G.; DEVENNY, D.A (eds.). Developmental time and timing. New Jersey: Lawrence Erlbaum Associates, 1993.

THOMAZ, R. Psicologia do esporte. Rio de Janeiro: Ao livro técnico, 1999.

TONELLO, M.G.M.; PELLEGRINI, A. M. A utilização da demonstração para a aprendizagem de habilidades motoras em aulas de Educação Física. Revista Paulista de Educação Física; São Paulo, v.12, n.2; p. 107-14, jul-dez. 1998.

WAJSKOP, G. O brincar na educação infantil. Cadernos de Pesquisa, São Paulo, n.92, p.62-69, 1995.

Recebido em: dezembro 2002 Aprovado para publicação em: julho 2004 